\title{
Cluster observes formation of high-beta plasma blobs
}

\author{
G. Haerendel $^{1,2}$, E. Georgescu ${ }^{2,3}$, K. H. Glassmeier ${ }^{4}$, B. Klecker ${ }^{2}$, Y. V. Bogdanova ${ }^{2,5}$, H. Rème ${ }^{6}$, and H. Frey ${ }^{7}$ \\ ${ }^{1}$ International University Bremen, Germany \\ ${ }^{2}$ Max-Planck-Institut für extraterrestrische Physik, 85741 Garching, Germany \\ ${ }^{3}$ Institute for Space Sciences, Bucharest, Romania \\ ${ }^{4}$ Institut für Geophysik und Meteorologie, TU Braunschweig, Germany \\ ${ }^{5}$ Mullard Space Science Laboratory, University College London, UK \\ ${ }^{6}$ Centre d'Etude Spatiale des Rayonnements, Toulouse, France \\ ${ }^{7}$ Space Sciences Laboratory, University of California, Berkeley, USA
}

Received: 19 November 2003 - Revised: 19 May 2004 - Accepted: 28 May 2004 - Published: 14 July 2004

Part of Special Issue "Spatio-temporal analysis and multipoint measurements in space"

\begin{abstract}
Late in a sequence of four moderate substorms on 26 July 2001, Cluster observed periods of a few minutes durations of high-beta plasma events $(B<10 \mathrm{nT}, \beta=2-30)$, connected with dipolarizations of the magnetic field. Cluster was located near 02:45 MLT, at $R=19 R_{E}$ and at about $5^{\circ} \mathrm{N}$ GSM. These events began late in the recovery phase of the second and about $5 \mathrm{~min}$ before onset of the third substorm and lasted for three hours, way beyond the recovery phase of the fourth substorm. The most remarkable observation is that the onset coincided with the arrival of energetic $(E \sim 7 \mathrm{keV}) \mathrm{O}^{+}$ions and energetic electrons obviously from the ionosphere, which tended to dominate the plasma composition throughout the remaining time. The magnetic flux and plasma transport is continuously directed equatorward and earthward, with oscillatory east-west movements superposed. Periods of the order of 5-10 min and strong correlations between the magnetic elevation angle and log $\beta$ (correlation coefficient 0.78 ) are highly reminiscent of the high-beta plasma blobs discovered with Equator-S and Geotail between 9 and $11 R_{E}$ in the late night/early morning sector (Haerendel et al., 1999).

We conclude that Cluster observed the plasma blob formation in the tail plasma sheet, which seems to occur predominantly in the recovery and post-recovery phases of substorms. This is consistent with the finding of Equator-S and Geotail. The origin is a pulsed earthward plasma transport with velocity amplitudes of only several tens of $\mathrm{km} / \mathrm{s}$.
\end{abstract}

Key words. Magnetospheric physics (plasma convection; plasma sheet; storms and substorms)

\section{Introduction}

The literature on substorms is huge, but it concentrates mainly on the onset and the expansion phase. The recovery

Correspondence to: E. Georgescu

(eg@mpe.mpg.de) and post-recovery phases find comparatively little attention. One of the most striking phenomena of the latter is the omega bands, protrusions or tongues of auroral emissions extending poleward from the post-midnight oval and drifting eastward at speeds between 0.4 and $2.0 \mathrm{~km} / \mathrm{s}$. The name was given by Akasofu and Kimball (1964) because the boundaries of the tongues are reminiscent of an inverted Greek letter $\Omega$. Related to the optical phenomena are the Ps6 magnetic pulsations with periods between 5 and $40 \mathrm{~min}$, mainly expressed in the $Y$ - and $Z$-components of the surface magnetic field (Saito, 1978). Simultaneous observations of $\Omega$-bands and Ps6 pulsations by Baumjohann (1979) and Opgenoorth et al. (1983) have led to models of the associated 3-D current system. Later measurements of the ionospheric electric field and conductances by use of the EISCAT radar provided a more detailed model of the current closure between Hall and Pedersen and field-aligned currents (Buchert et al., 1990). The first report on related magnetospheric activity was provided by Steen et al. (1988), who observed strong modulations in the intensity of energetic electrons $(E>1 \mathrm{keV})$ at the geostationary orbit $\left(6.6 R_{E}\right)$. However, according to Pulkkinen et al. (1991), omega bands project mainly to larger equatorial distances, namely 6-13 $R_{E}$. In this range, more precisely between 9 and $11.5 R_{E}$, Haerendel et al. (1999) found striking plasma and magnetic field variations in the morning sector reaching beta values of 10 and more. They were shown to have an antisymmetric structure with respect to the equator, to drift eastward with speeds of typically $20 \mathrm{~km} / \mathrm{s}$ and to have lifetimes of at least $15-30 \mathrm{~min}$. These high-beta structures were named plasma blobs and were later identified as magnetospheric counterparts of Ps6 pulsations (i.e. also $\Omega$ bands) by Vaivads et al. (2001b).

A particularly noteworthy feature of the high-beta plasma blobs is their preferred occurrence during magnetically quiet periods (Haerendel et al., 1999). If the plasma was injected during a preceding substorm, their lifetimes must be very long, i.e. the associated field-aligned currents weak. Otherwise, the associated Poynting flux into the ionosphere would 


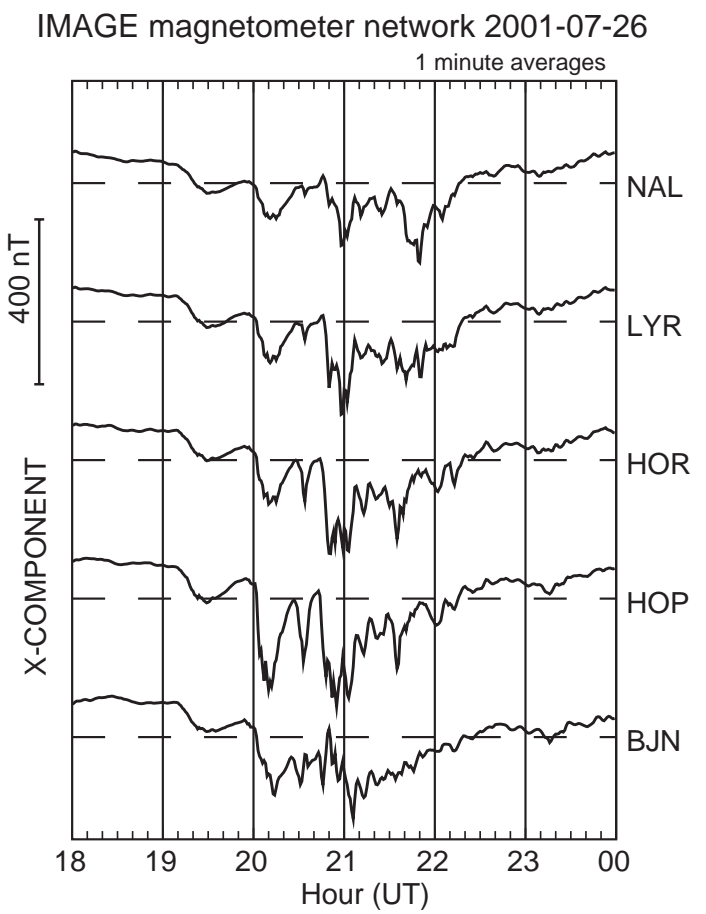

High beta events

Fig. 1. IMAGE magnetometer data for 26 July 2001, 18:00-24:00 UT, $X$-components only.

cause fast damping (see also Vaivads et al., 2001b). In other words, while the plasma blobs may relate to Ps6 pulsations, they do not necessarily create optical emissions like $\Omega$-bands. This is probably restricted to the recovery phase of substorms. Finally, it must be noted that Haerendel et al. (1999) concluded that the high-beta plasma blobs must exist out to the morningside magnetopause.

In this paper we report Cluster observations at $19 R_{E}$ of high-beta plasma events of a few minutes duration which are quite reminiscent of the plasma blobs found with Equator-S at 9 to $11 R_{E}$. They seem to originate in the recovery period of a substorm within the morning section of the decaying substorm current wedge. The most striking similarities with the plasma blobs closer to the Earth are the correlation between magnetic elevation angle and plasma beta, sloshing motions of the plasma along the field lines, and the persistence into quiet periods. What is different is the lack of a steady eastward motion which characterizes the plasma blobs further inward. At $19 R_{E}$ a persistent earthward motion was found. We, therefore, suggest that Cluster encountered the source region of plasma blobs/Ps6 pulsations. If this identification holds out, it will have an impact on the interpretation of the Ps6 pulsations and plasma tongues in the $\Omega$-bands. They have been related most often to KelvinHelmholtz instabilities (e.g. Rostoker and Samson, 1984), to an electrostatic interchange instability (Yamamoto et al., $1993,1997)$, or, in case of the potentially associated compressional Pc5 waves, to a drift mirror instability (Hasegawa, 1969; Baumjohann et al., 1987). In all these cases one would expect the plasma to move outward rather than earthward inside the high-beta region. For this reason, we will offer a different interpretation.

\section{Instrumentation}

In this paper we use mainly 1 spin ( $4 \mathrm{~s}$ ) averages of the magnetic field measured with the fluxgate magnetometers (FGM) on board Cluster (Balogh et al., 2001) from all four Cluster spacecraft. The proton and oxygen data are from the Cluster Ion Spectrometer (CIS) on board spacecraft 1, 3, and 4. The CIS sensor comprises (Rème et al., 2001) (1) a time of flight mass spectrometer, CIS-1, which combines a top-hat analyzer with an instantaneous $360 \times 8^{\circ}$ field-of-view with a time-of-flight section to measure complete 3-D distribution functions of the major ion species $\mathrm{H}^{+}, \mathrm{He}^{++}, \mathrm{He}^{+}$and $\mathrm{O}^{+}$ in the energy range between 0.02 and $38 \mathrm{keV} / \mathrm{q}$, (2) a Hot Ion Analyzer, CIS-2, measuring the ions' distribution from $5 \mathrm{eV}$ to $26 \mathrm{keV}$ by combining a classical symmetrical quadrispherical analyzer with a fast particle imaging system based on microchannel plate electron multipliers and position encoding.

\section{Geophysical conditions}

The period under consideration (26 July 2001, 18:0023:00 UT) was only mildly geomagnetically disturbed. After $3.5 \mathrm{~h}$ of very quiet conditions, AL dropped to about $-160 \mathrm{nT}$ between 18:00 and 18:25 UT and after that recovered towards about $-20 \mathrm{nT}$ by 22:00 UT. This reflects the behavior of the IMF $B_{z}$ as measured by the ACE spacecraft at the L1 position. It had been positive between 12:30 and 17:00 UT, then turned negative and remained so until about 22:30 UT with $\Theta_{B, G S M}>-40^{\circ}$.

The IMAGE magnetometer network in Scandinavia and Finland registered a sequence of substorms, the first of which began at 19:10 UT, when Cluster was about five hours further to the east (Fig. 1). In the area covered by this network, the second substorm and the first local one began at 20:02 UT, corresponding to about 22:30 MLT, and lasted for about $1 / 2 \mathrm{~h}$. The auroral electrojet (AEJ) was centered far to the north near Hopen Island (magn. lat. 73.06). The third substorm, commencing at 20:47 UT, was centered even slightly further north. A fourth substorm followed at 21:40 UT and subsided at 22:20 UT, about the time of $B_{z}$ turning positive. The AEJ was centered well north of Ny Alesund $\left(\lambda_{\text {magn }}=75.25\right)$. The maximum excursions of the negative $X$-component stayed below $200 \mathrm{nT}$.

The IMAGE satellite covered only the first two substorms until 20:22 UT. The second one started a few minutes earlier than the beginning of the expansion phase as registered by the IMAGE magnetometer network. Figure 2 shows three frames covering this event. It started near midnight and expanded west- and eastward and also to the north, up to about $76^{\circ}$ by $20: 11$ UT. This is consistent with the ground magnetograms. 


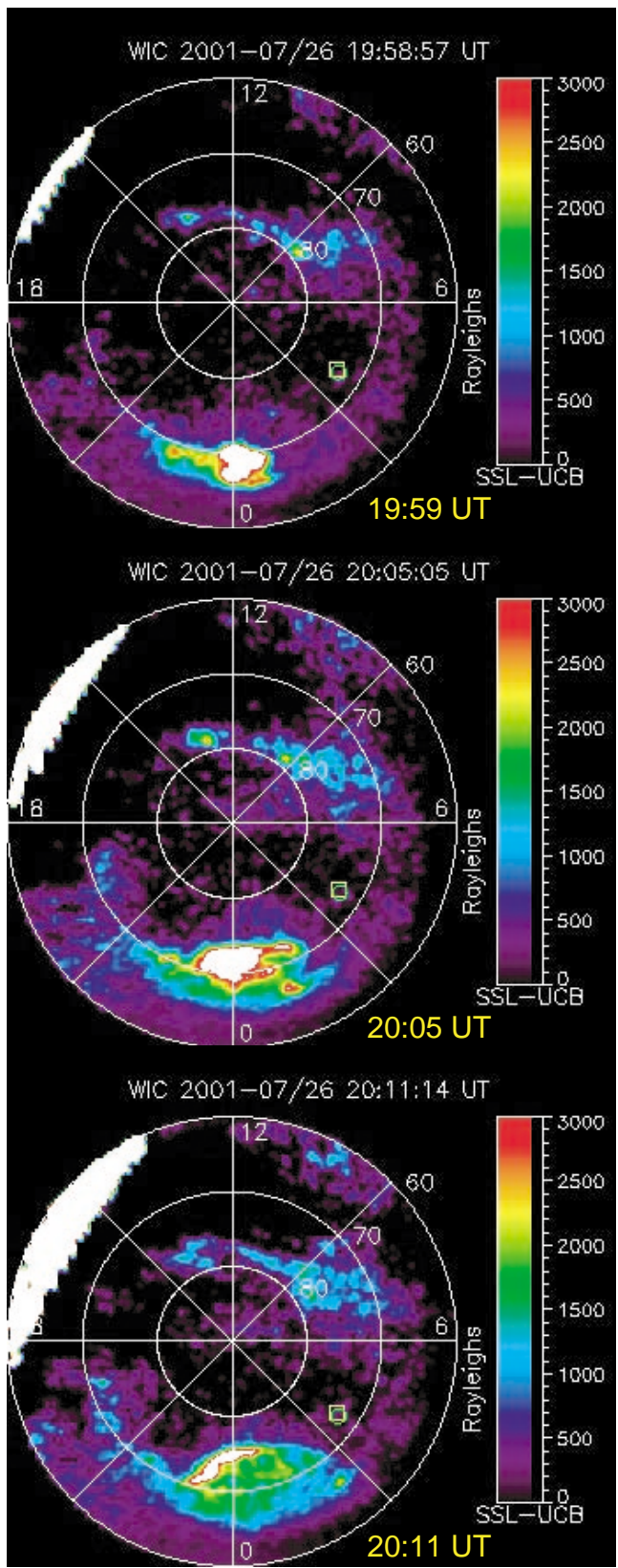

Fig. 2. IMAGE/FUV images for the second substorm on 26 July 2001 in geomagnetic latitude-MLT projection.

In summary, Cluster experienced a sequence of four moderate substorms centered around midnight while being a few hours further into the late night sector and located near the northern edge of the plasma sheet at a distance of about $19 R_{E}$.

\section{Overview of Cluster observations}

Figure 3 shows, for four hours and in polar GSM coordinates, the magnetic field, measured by all four Cluster spacecraft, and from S/C 1, 3, and 4, proton density, $N_{p}$, plasma pressure, $P_{\text {plasma }-p}$, and total pressure, $P_{\text {tot }-p}$, based on these data sets, and the plasma beta. During the first substorm,

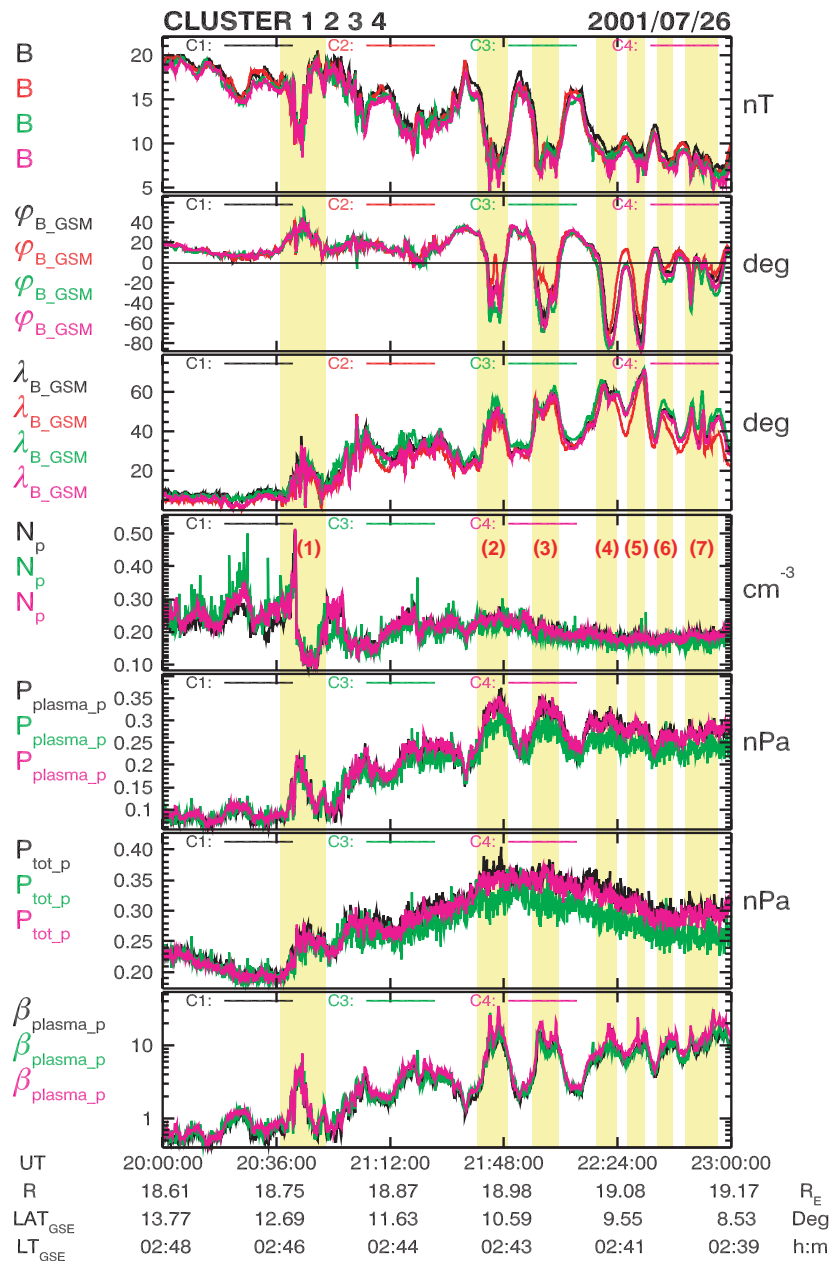

Fig. 3. FGM magnetic field data in polar GSM coordinates $(\boldsymbol{B}$, $\delta, \varphi)$ and CIS proton data (density, plasma pressure, total pressure and plasma $\beta$ ) for the 4 Cluster spacecraft for 26 July 2001, 20:00 23:00 UT. The colors of traces, conform convention, are black, red, green, and magenta for Cluster 1, 2, 3, and 4, respectively.

Cluster seems to have still been in the northern tail lobe. At 19:51 UT (not shown) the magnitude of $\boldsymbol{B}$ drops slightly and plasma density and pressure rise markedly. Cluster entered the plasma sheet, probably unrelated to the onset of the second substorm a few minutes later. Otherwise, nothing remarkable happened until 20:42 UT.

This time marks the beginning of the period of events on which this paper focuses. In Figs. 3 and 7, they have been marked with $(j), j=1-7$. These events are characterized by a few minutes of strong directional changes of $\boldsymbol{B}$ coincident with decreases of $|\boldsymbol{B}|$ and rises in beta. The most dramatic change in the data when entering into this period is seen in the spectral distribution and flux of energetic electrons (20$40 \mathrm{keV}$ ) (Fig. 4) as measured with the PEACE and RAPID experiments (Escoubet et al., 1997) and the flux of $\mathrm{O}^{+}$ions (Fig. 5). After 20:42 UT the oxygen flux rises gradually from insignificant background counts to densities of about $0.01 \mathrm{~cm}^{-3}$. This means that the mass density of $\mathrm{O}^{+}$is almost comparable to that of the protons, and stays at this level until 


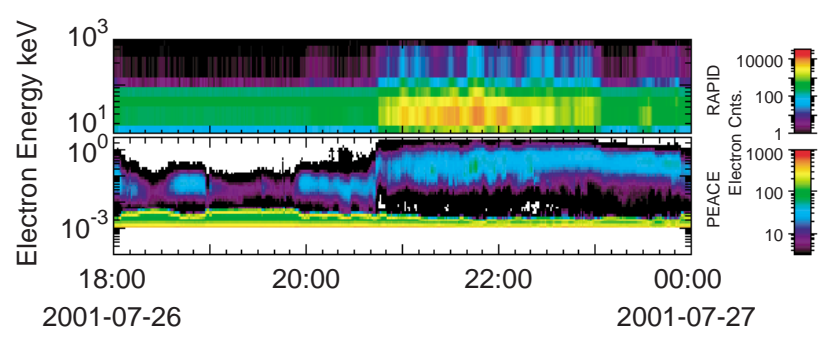

Fig. 4. Energetic electron spectrograms from PEACE $\left(10^{-} 2-30 \mathrm{keV}\right)$ and RAPID $\left(10-10^{3} \mathrm{keV}\right)$ experiments.

a few minutes before midnight. The mean energy of the $\mathrm{O}^{+}$ ions is near $7 \mathrm{keV}$. We can thus state that the period before 20:42 UT is $\mathrm{H}^{+}$-dominated and the period after is strongly $\mathrm{O}^{+}$-enriched, as far as the mass density is concerned. One might be tempted to speculate that the presence of a strong hot $\mathrm{O}^{+}$-component is causally related to the events to be discussed subsequently. However, we will argue that it is only indicative of the nature of the plasma environment, as is the high electron temperature of about $2 \mathrm{keV}$ in the region under investigation.

\section{The arrival of $\mathrm{O}^{+}$-ions}

We will now have a closer look at the field, plasma and flow signatures of event (1), characterized by the arrival of $\mathrm{O}^{+}$. Figure 6 shows the plasma and field data during the interval of interest, 20:35-20:50 UT, somewhat expanded. The event begins at 20:39 UT with a change in the magnetic field vector followed by a fast increase in $\mathrm{H}^{+}$-density and pressure. The azimuth and magnetic elevation angles increase, whereas the magnitude of $\boldsymbol{B}$ falls. At this time, no significant flux of $\mathrm{O}^{+}$is yet visible. Three minutes later, at 20:42 UT, the $\mathrm{H}^{+}$density falls dramatically from $0.5 \mathrm{~cm}^{-3}$ to $0.2 \mathrm{~cm}^{-3}$, while plasma pressure and beta rise equally fast to a maximum. The proton temperature (not shown) rises by a factor of about 4 , while $|\boldsymbol{B}|$ stays at a minimum of $12 \mathrm{nT}$ for $3 \mathrm{~min}$. This is the time of $\mathrm{O}^{+}$arrival. After 20:45 UT all quantities begin to return to the undisturbed level, which is reached at 20:50 UT. Here, $\mathrm{O}^{+}$shows a few minutes drop-out. Immediately after 20:50 UT $\lambda_{\text {magn }}$ begins to rise again to be followed by plasma pressure and beta, whereas $|\boldsymbol{B}|$ and $N_{p}$ (i.e. $\mathrm{H}^{+}$-density) drop again. The prominent feature of the period from 20:35 to 21:00 UT is the arrival of $\mathrm{O}^{+}$.

Where does the $\mathrm{O}^{+}$come from? Most likely from the ionosphere. This is, indeed, supported by the flow velocity vector calculated on the ground from the $\mathrm{H}^{+}$energy distributions measured by the CODIF sensor of the CIS-experiments. Figure 7 shows separately the three cartesian (GSM) coordinates of the transverse and parallel proton flow velocities. The arrival of the $\mathrm{O}^{+}$-ions appears as the most pronounced event in the $\mathrm{H}^{+}$-based velocity data until 23:40 UT, when Cluster crossed briefly the neutral sheet (not shown here). Between 20:42 and 20:52 UT, i.e. at the time of $\mathrm{O}^{+}$arrival, a
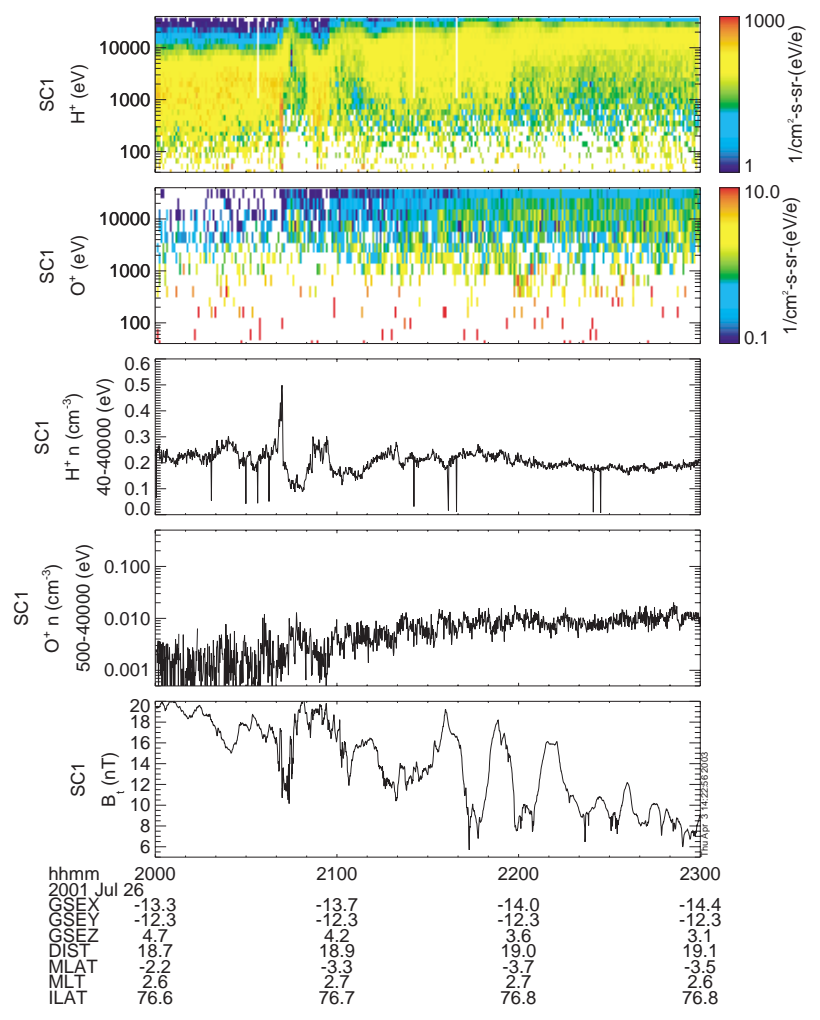

Fig. 5. Oxygen data (CIS experiment) for Cluster 1. Panels show proton and oxygen spectrograms, densities and the FGM magnetic field strength.

clear flow antiparallel to $\boldsymbol{B}$ is observed in the $\mathrm{H}^{+}$-component with a peak value (except for a very narrow spike) of about $160 \mathrm{~km} / \mathrm{s}$. This is consistent with the assumption that Cluster encountered the arrival of plasma freshly injected from the ionosphere.

At about 20:38 UT, the transverse flow component (Fig. 7) starts to rise from a near-zero level $(\leq 30 \mathrm{~km} / \mathrm{s})$ to values up to and above $200 \mathrm{~km} / \mathrm{s}$ in the positive $x$ - and negative $y$ - and $z$-directions, more or less in phase with the increasing elevation and azimuth angles of the magnetic field. The $V_{\perp x}$ and $V_{\perp z}$-components are consistent with the observed dipolarization of the magnetic field under frozen-in conditions. The negative $V_{\perp y}$-component, on the other hand, indicates an arrival of the perturbation from earlier hours, i.e. from the midnight sector. By 20:46 UT, $\boldsymbol{V}_{\perp}$ reverses rapidly its direction, most pronounced in the y-component. A few minutes after, $\mathrm{O}^{+}$is seen to drop out for another few minutes. This observation can be interpreted as a short-term rebounce of an $\mathrm{O}^{+}$-loaded flux-tube which had been convected to the Cluster position from the midnight sector. By 20:55 UT the previously seen eastward motion, connected with a reappearance of $\mathrm{O}^{+}$and a dipolarization of $\boldsymbol{B}$, is resumed and lasts for about $8 \mathrm{~min}$. No parallel flow is observed anymore at this time, as if the plasma had come to rest except for a slow eastward convection. The magnetic elevation angle stays near $35^{\circ}$ and the azimuth close to its nominal value for the local time. 


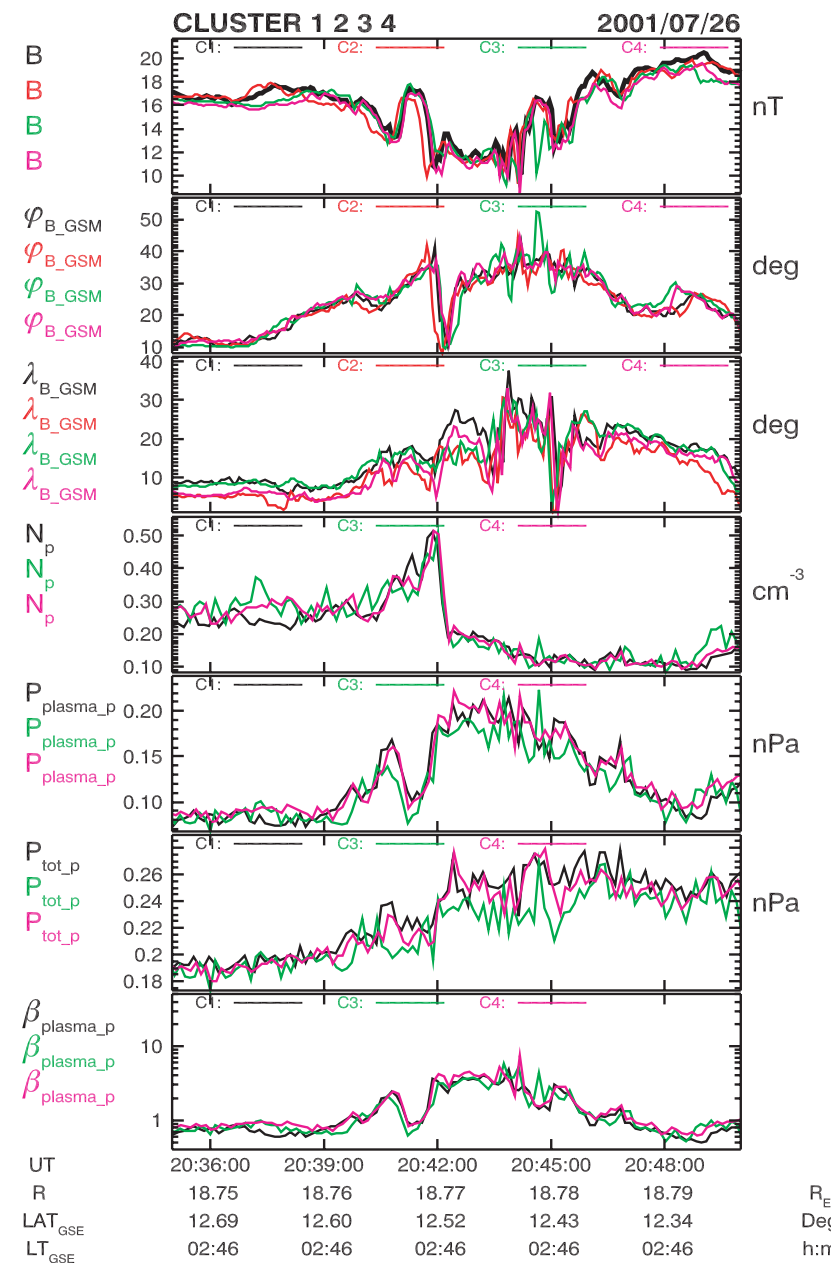

Fig. 6. FGM magnetic field data in polar GSM coordinates $(B, \delta, \varphi)$ and CIS proton data (density, plasma pressure, total pressure, and plasma $\beta$ ) for the 4 Cluster spacecraft for 26 July 2001, 20:3520:50 UT)(event \#1). The colors of traces, conform convention, are black, red, green, and magenta for Cluster 1, 2, 3, and 4, respectively.

The just described plasma and field data from the period 20:38 until 21:03 UT can be consistently interpreted as showing the convective transport of magnetic field loaded with hot $\mathrm{O}^{+}$-enriched plasma, from earlier local times, a short rebounce, and a reappearance. Particular attention should be paid to the change in the magnetic azimuth angle during this event. Before 20:38 UT, $\varphi_{G S M}$ varied between $+10^{\circ}$ and $+20^{\circ}$ which is close to the expected pointing at 02:45 MLT. With the beginning plasma pressure increase and magnetic field decrease and dipolarization, the azimuth angle rises up to $40^{\circ}$. Figure 8 a shows a sketch of the likely magnetic field configuration before 20:38 and at 20:44 UT, the time of maximum field distortion. The observed parallel and transverse flow vectors at 20:44 UT are shown as well.

The observed bending of the magnetic field lines so that the more distant section is leading in the sense of the azimuthal plasma convection (Fig. 8a) suggests that the driving forces of field deformation and plasma motion have been applied from mostly outside the Cluster position. The aver-

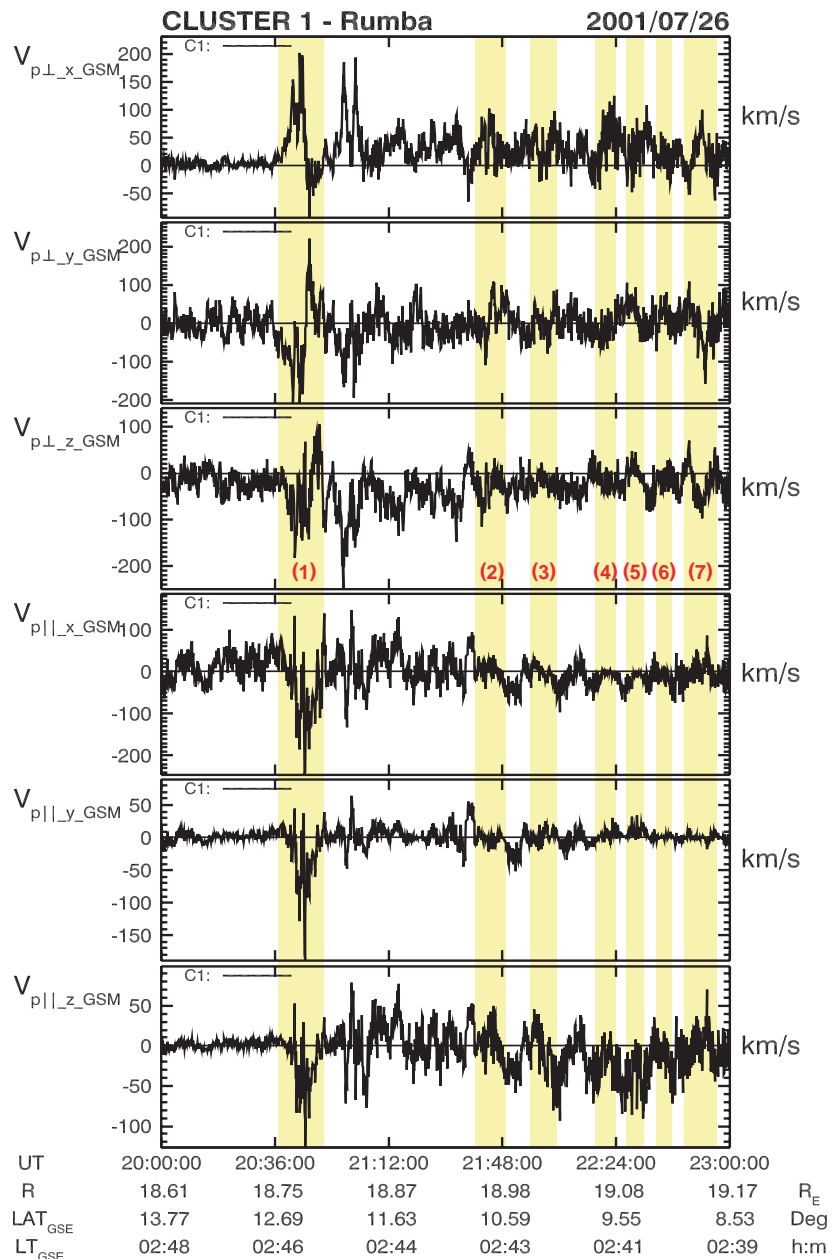

Fig. 7. Plasma velocity perpendicular (in the three upper panels) and parallel (in the three lower panels) to the magnetic field in Cartesian GSM coordinates.

age eastward convection velocity during the interval 20:3620:46 UT was about $40 \mathrm{~km} / \mathrm{s}$, corresponding to a displacement of $24000 \mathrm{~km}$ or $3.75 R_{E}$. At a distance of $18.8 R_{E}$, this corresponds to an eastward displacement of $\sim 12.5^{\circ}$ or 50 min MLT. The short reversed flow from 20:46 until 20:51 UT occurred with a similar average speed, but lasted only half as long. This means that the rebounce motion covered only about half the length of the initial eastward displacement. Subsequently, the eastward motion was resumed. For the $10 \mathrm{~min}$ of strong antiparallel, i.e. outward directed, flow (20:42-20:52 UT), the average speed was near $60 \mathrm{~km} / \mathrm{s}$, corresponding to a parallel displacement of 5 to $6 R_{E}$. The absence of a noticeable parallel flow upon the return of $\mathrm{O}^{+}$ indicates that the plasma had come to rest. Actually, careful inspection of the data for the following half hour reveals some short-term oscillations of $\boldsymbol{V}_{\|}$and a longer, coherent return flow component (parallel $\boldsymbol{B}$ ) between 21:06 and 21:47 UT, as if the plasma was sloshing back towards northern latitudes. 


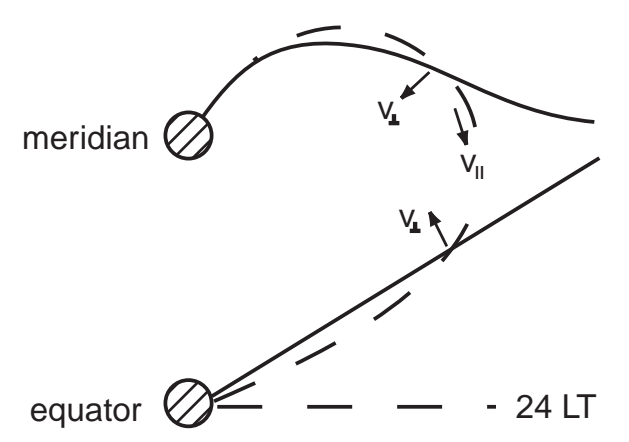

(a)
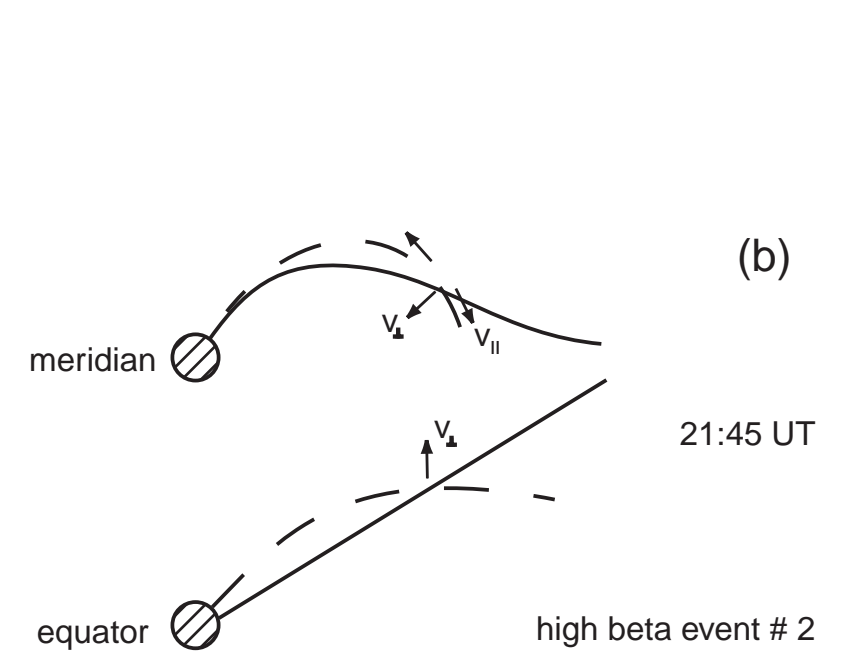

Fig. 8. Sketches of magnetic field lines for events \#1 (a) and \#2 (b).

\section{Subsequent high-beta events}

The period following the arrival of $\mathrm{O}^{+}$until about 23:00 UT contains some striking events of 7 to 10 min duration, numbered (2) to (7), whose most prominent characteristics are a strong increase in the magnetic elevation angle, $\lambda_{B}$, up to and beyond $60^{\circ}$ in phase with a strong increase of beta up to and above 10, while the total pressure, plasma plus magnetic, is nearly unaffected (Fig. 3). Also in phase with $\lambda_{B}$ is a strong excursion of the azimuth angle, $\varphi_{B}$, into negative values. While the behavior of $\lambda_{B}$ and beta in these events is quite similar to that at the arrival of $\mathrm{O}^{+}$(event 1$), \varphi_{B}$ changes in the opposite direction. The field is pointing towards late morning hours.

Throughout the period from 21:30 until 23:00 UT, during which these events were observed, the transverse plasma velocity has dominantly positive $x$ - and negative $z$-components (Fig. 7). This tendency is even more clearly expressed during the period between $\mathrm{O}^{+}$-arrival and the first of the here discussed events (2), i.e. from 21:00 to 21:30 UT. This means that the plasma and field transport is essentially earthward and equatorward, as sketched in Fig. 8b. The longitudinal transport is less clear, but there is a tendency for $V_{\perp y}$ to be negative, i.e. to point eastward, prior to and in the first half of event (2), and positive in the second half. For the subsequent events, no clear tendency is observed. The plasma is more

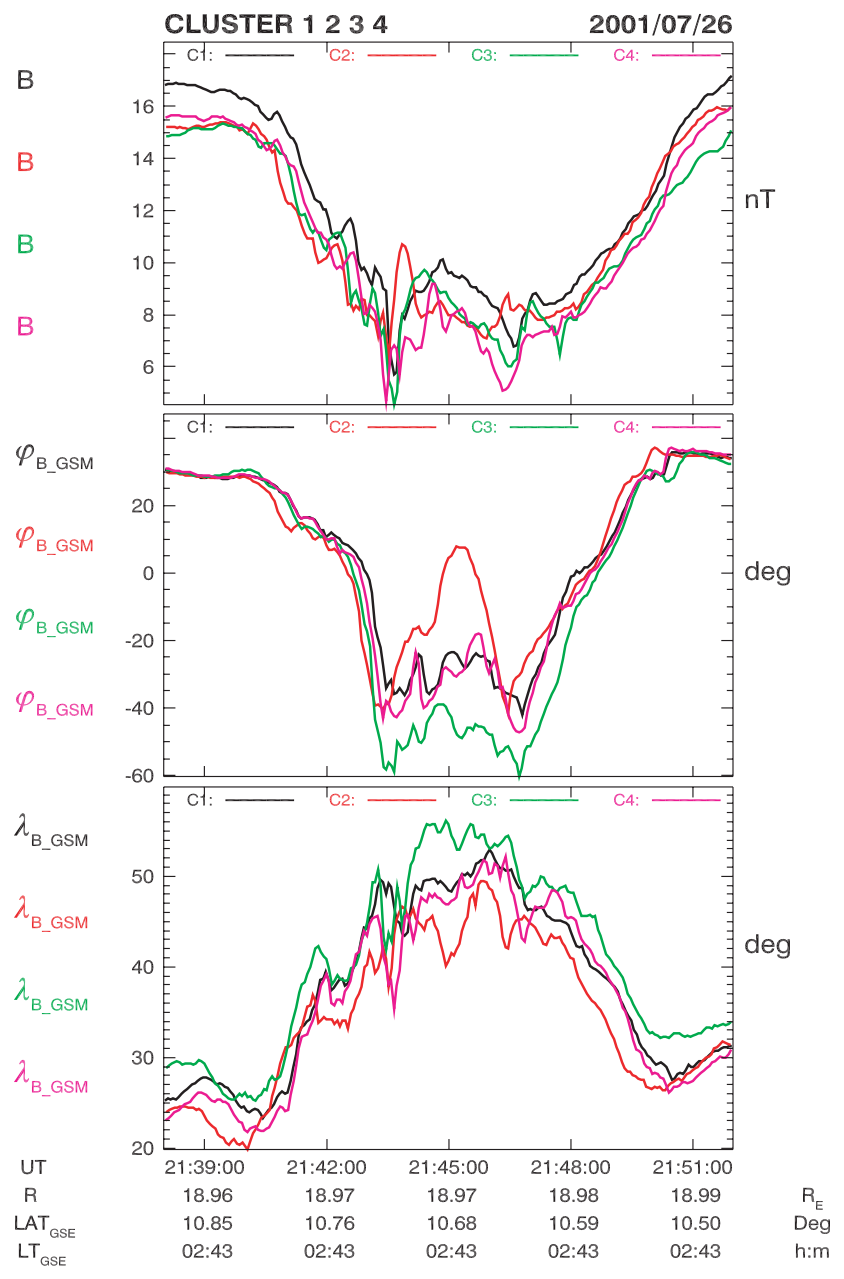

Fig. 9. Magnetic field (FGM data) in polar GSM coordinates for event \#1.

or less stagnant, with the average velocity in $+y$-direction between 21:40 and 23:00 UT being about $4 \mathrm{~km} / \mathrm{s}$. The more surprising are the strong negative excursions of the magnetic field vector in azimuth which is such a prominent feature of events (2)-(7). A simple interpretation is that Cluster is located close to a node of the distorting motion of the field lines.

The diagram in Fig. 8 suggests that the low-altitude motion is eastward ( $-y$-direction) and the high-altitude motion, i.e. outside the Cluster position, slowly westward $(+y$-direction). This is not inconsistent with the instantaneous y-components of the transverse plasma flow during event (2), which is mostly positive. But this is not at all shared by the later events. Apart from the correlation of beta and $\lambda_{B}$, and the generally earthward convection, events (2) to (7) exhibit a different behavior from that of the $\mathrm{O}^{+}$-arrival (event 1). Obviously there was a massive eastward transport of the plasma which came to rest and was more or less stagnating during the subsequent two hours with respect to the E-W motions while consistent by moving earthward. 
The parallel ion flow during the later events is also not very clear-cut. One observes velocities away from and towards the equator. For events (2) and (3), the field-aligned flow appears to turn around in the middle of the event from earthward to equatorward, as if the plasma was sloshing between the Southern and Northern Hemispheres.

\section{Four-spacecraft observations}

So far, we have treated the data as if they were obtained with one satellite only. The phasing of changes in $\boldsymbol{B}$, beta, etc. at the four Cluster spacecraft may provide additional insight. Such a task is relatively easy if the observed phenomenon has a well-defined surface or 3-D-shape. This is obviously not the case here. Therefore, our insights are of limited significance. However, we can at least test whether the sequence of entrance into and exit out of the high-beta structures is consistent with the earlier deductions from the transverse velocities. We will inspect only the $\mathrm{O}^{+}$-arrival period and event \#2.

Event \#1: $\mathrm{O}^{+}$-Arrival. The onset of the depression in $|\boldsymbol{B}|$ at 20:41:30 UT is observed in the sequence, S/C 2 (20:41:36.3 UT), S/C 1 (20:41:49 UT), S/C 4 (20:41:51 UT), S/C 3 (20:41:54 UT), i.e. S/C 2 was hit by the high-beta region well before the other three S/C whose entry occurred within $5 \mathrm{~s}$ (Fig. 6). In other words, the boundary of the arriving high-beta region was oriented more or less parallel to the plane constituted by S/C 1,3 , and 4 . S/C 2 was at a distance of $1624 \mathrm{~km}$ from this plane in the direction of 21:00 LT and of $41^{\circ}$ above the GSM equatorial plane. This means that the high-beta plasma arrived approximately from this direction, quite consistent with the above evaluation of the plasma flow velocities. An average delay time of $15 \mathrm{~s}$ yields a progression velocity of $\sim 110 \mathrm{~km} / \mathrm{s}$, in good agreement with the measured plasma flow velocity.

The exit velocity at 20:45:30 UT follows approximately the same sequence, S/C 2, 1, 4, 3, but it is not as clearcut as during the entry. In between, i.e. during the time of strong magnetic field depression and the arrival of $\mathrm{O}^{+}$-ions, one sees a high variability of $\boldsymbol{B}$. It is extremely difficult to make sense out of the sequencing of similar variations seen at the four spacecraft. One prominent minimum in $\boldsymbol{B}$ seen at S/C 3 at 20:44:37 UT (green contour) has no counterpart at the other 3 spacecraft. This whole behavior clearly suggests that the high-beta region is not simply passing through the position of Cluster, but is strongly evolving by structured parallel and transverse mass transport.

Event \#2: The entry of Cluster into the depressed $\boldsymbol{B}$-region at 21:41 UT shows a different sequence of events, namely S/C 2, 3, 4, 1 with more or less equal separation periods, in total about $30 \mathrm{~s} \mathrm{(Fig.} \mathrm{9).} \mathrm{This} \mathrm{suggests} \mathrm{a} \mathrm{propagation} \mathrm{ve-}$ locity of the order of $60-70 \mathrm{~km} / \mathrm{s}$. If interpreted as a planar front, its normal vector must have pointed at $\varphi=-30^{\circ}$ with $\lambda=-10^{\circ}$. At the exit from this event, the sequence is 2,1 , 4,3 , if derived from the fast change in the elevation angle. Again, the behavior of the magnetic field is quite confusing

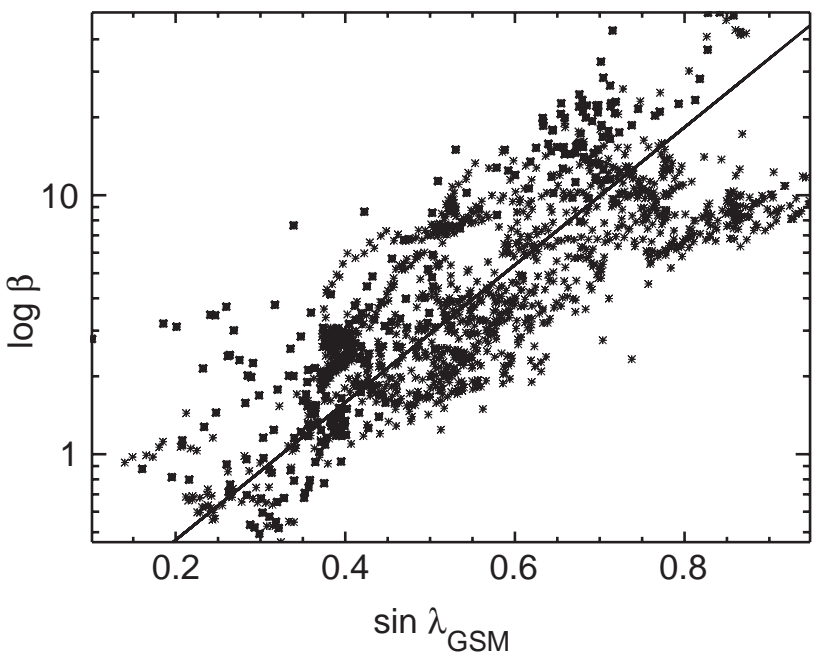

Fig. 10. Correlation between $\log \beta$ and sinus of magnetic field elevation $\left(\delta_{G S M}\right)$ for the period 20:40-24:00 UT.

and does not lend itself to an interpretation in terms of simple geometric shapes of the high-beta events, much in contrast to the plasma blobs observed by Equator-S. In other words, the plasma is in a rather agitated state.

\section{Discussion and interpretation}

On 26 July 2001, the Cluster S/C met very pronounced changes in the field and plasma quantities at a position within the plasma sheet at $19 R_{E}, 03: 00 \mathrm{MLT}$, and $\sim 5^{\circ} \mathrm{N}$ GSM. Most striking were the in-phase increases of magnetic elevation angle and beta.

Figure 10 shows the correlation of $\log \beta$ and $\sin \lambda$ for the time interval 20:40-24:00 UT, the correlation coefficient being 0.78. At the same time, the azimuth angle of $\boldsymbol{B}$ changed as well, but for the first event in the positive and for the later ones (2-7) in the negative sense. This is demonstrated in Fig. 11 which contains the azimuth, $\varphi$, and elevation, $\lambda$, data in GSM coordinates for the interval 21:40-23:00 UT, i.e. excluding the $\mathrm{O}^{+}$-arrival event. Here the correlation coefficient is -0.88 . While the correlation between high $\beta$-values and elevation demonstrates the not surprising fact that dipolarizations of the magnetic field are connected with earthward plasma transport and compression, the further correlation with changes in the field azimuth contains information on the forces driving the E-W convection of plasma and field. As discussed above and sketched in Fig. 8a, the positive excursion of $\varphi$, in conjunction with an eastward convective flow, as observed in event \#1, implies a dragging of the flux-tubes by eastward directed forces outside and equatorward of the position of Cluster, which is not the case during the subsequent events \#2-7, as seen in Fig. 11. First, the field is bent into the negative $\varphi$-direction, and no appreciable and systematic convective flow has been observed during these events. This absence of in-phase motion has been interpreted above 


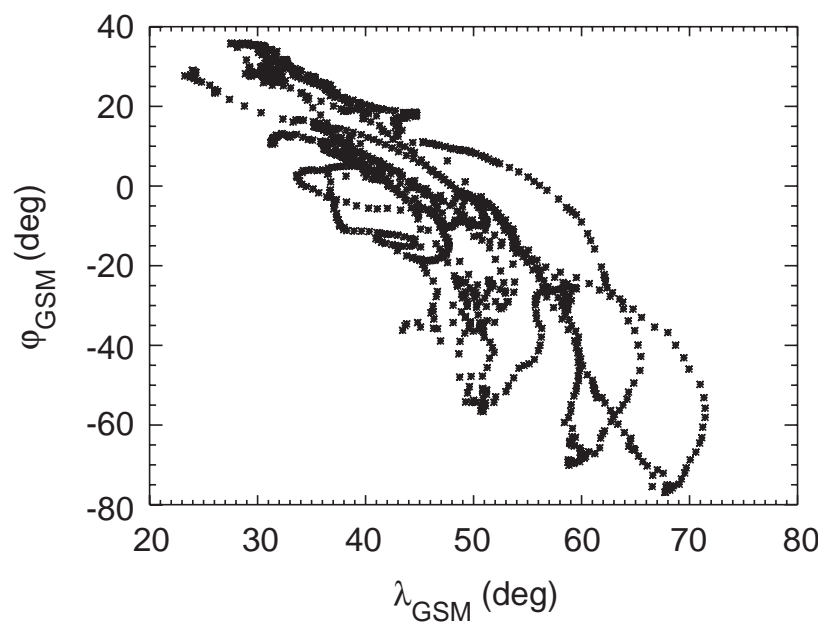

Fig. 11. Correlation between magnetic field azimuth and elevation in GSM during the period of events \#2 to 7 (21:40-23:00 UT). Correlation coefficient is 0.88 .

as indicating that Cluster was near a node of the magnetic field line distortions. The negative sign of $\Delta \varphi$ then means that this distortion was enforced from below, probably as a result of an eastward convection in the ionosphere which is not shared by the flux-tubes' high-altitude portions. Opposing pressure forces may be acting there.

A better insight into the nature of the high-beta events and the conditions for their appearance can be obtained, if we integrate the $y$-component of the perpendicular velocity, $V_{\perp y}$, over time. Under the frozen-field assumption, this yields a measure of the E-W distance of the position of Cluster from the edge of the eastward expanding region filled with $\mathrm{O}^{+}$-ions and containing the high-beta events. Figure 12 shows this distance, $S p-y$, as a function of time. The eastward convection began at about 20:38 UT and stopped at 21:40 UT, at the time of event \#2. The edge had moved by $70000 \mathrm{~km}$ in the $-y$-direction, which is equivalent to a separation by $1.5 \mathrm{~h}$ in local time. At the position of Cluster, maximum pressure had been reached, while the temperature continued to rise slowly for another $45 \mathrm{~min}$.

A better view of the spatial structure is provided by plotting the proton temperature measurements versus distance, $S p-y$, from the leading edge, as done in Fig. 13. The color coding is consistent with that of Fig. 12 and allows the association with the times of recording. One finds a sharp increase in temperature at a distance of about $30000 \mathrm{~km}$ or about $1 / 2 \mathrm{~h}$ from the passage of the leading edge. $T_{\perp}$ rose from an average of $25 \mathrm{MK}$ to a mean temperature of $80 \mathrm{MK}$ with a broad range of fluctuations, but no discernable spatial trend.

What one learns from these considerations is that the highbeta events under investigation are embedded in a broad substorm wedge of several hours local time extent characterized by high pressure due to a strong rise in temperature under the reduction of the density (cf. Fig. 3) . The eastern edge of this region passed the Cluster position in the late recovery

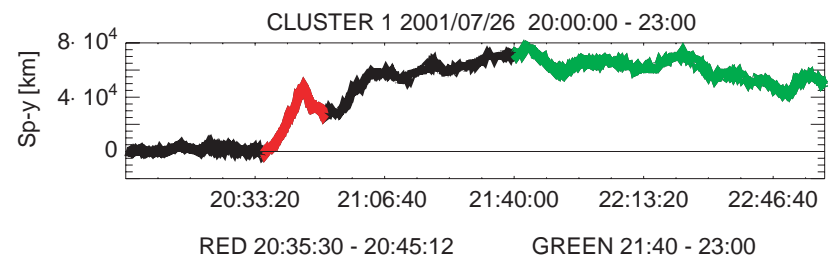

Fig. 12. Separation distance $(S p-y)$ of the leading edge of the eastward expanding substorm wedge to the Cluster location versus time.

phase of the second substorm and several minutes before the onset of the third substorm (20:47 UT). The edge was followed by the first high- $\beta$ event. It coincided with the arrival of $\mathrm{O}^{+}$-ions of several $\mathrm{keV}$ mean energy, which persisted for the whole period of interest and made a strong contribution to the mass density. These ions had been convected towards the location of Cluster from earlier hours and, as evidenced by the parallel velocity, from lower altitudes. Although the high-beta events started in the middle of a sequence of four mild substorms, no close relation with the substorm activity could be discerned. The events continued into the quiet period after the substorms, albeit with decreasing amplitude of the excursions in $\lambda, \varphi$, and $\beta$. On the other hand, it is obvious that the energetic $\mathrm{O}^{+}$-ions must have originated from the ionosphere and their acceleration must have been powered by the substorm energy.

Indeed, it is most likely that the energetic $\mathrm{O}^{+}$-ions were accelerated in the ionosphere in the course of the second substorm (onset shortly before 20:02 UT) which, according to the IMAGE-FUV observations, was centered near midnight, i.e. three hours earlier in local time, and at about five degrees lower latitude than the magnetic footprints of the Cluster position. (The third substorm, on the other hand, began after the $\mathrm{O}^{+}$-arrival.) By about 20:11 UT, the second substorm had expanded sufficiently far pole- and eastward to come close to the Cluster field lines (see Fig. 2). The travel time of $7 \mathrm{keV}$ $\mathrm{O}^{+}$-ions to the Cluster position, if directly injected upward, would be only about $8 \mathrm{~min}$. The delay until their arrival at Cluster can only be attributed to a still existing longitudinal separation of the field lines of injection from the Cluster position by a few degrees. During the $6 \mathrm{~min}$ prior to the appearance of $\mathrm{O}^{+}$at 20:42 UT, the $y$-component of $\boldsymbol{V}_{\perp}$ rose from 0 to $90 \mathrm{~km} / \mathrm{s}$ eastward (Fig. 7), covering about $30000 \mathrm{~km}$ (see Fig. 12) or more than $1 \mathrm{~h}$ in local time. This supports strongly our conclusion that Cluster became immersed in an eastward expanding substorm wedge.

After the $\mathrm{O}^{+}$-plasma flows had settled, only smaller fieldaligned flows were observed, with alternating directions (max. amplitudes $\sim 50 \mathrm{~km} / \mathrm{s}$ ), indicating a sloshing between hemispheres with a superposed flow outward. The transverse motions were consistently directed earthward, i.e. towards lower $L$-values while more or less stagnating in local time. Since the $\mathrm{O}^{+}$-ions persisted throughout this period, we can conclude that the flux-tubes carried inward towards the position of Cluster had been loaded with ionospheric plasma prior to these events. 
What has been described so far, the changes in field orientation with increasing plasma beta (decreasing $\boldsymbol{B}$ ) and the field-aligned sloshing motions, is very reminiscent of the characteristics of the so-called plasma blobs or compressional Pc5 pulsations found with the Equator-S and Geotail spacecraft in the same local time sector between 9 and $11.5 R_{E}$ (Haerendel et al., 1999; Vaivads, et al., 2001a). The high-beta plasma regions were found to have an antisymmetric structure with respect to the equator, to have a longitudinal width of $5-10^{\circ}$, and to drift slowly eastward. The latter property, however, is not shared by the events at $19 R_{E}$ reported here. They are dominated by inward transport and stagnation in longitude. Hence, it is tempting to conclude that what we see here is the formation phase of the blobs some 8 to $10 R_{E}$ further outward. The observation of a very irregular internal structure at Cluster distance supports the view that the blobs are forming here, while later, once the high-beta plasma has penetrated towards $11 R_{E}$ and further inward, it has quieted down and assumed a more orderly spatial structure.

A question that could not be answered from the observations with Equator-S and Geotail pertains to the origin of the plasma blobs. The Cluster observations reported here, if correctly identified as showing the formation phase of these blobs, may carry us a step forward. Undoubtedly, they are related to substorms, but they extend well beyond the actual substorm activity, closer to the Earth, even for several hours (Haerendel et al., 1999). Obviously, the hot plasma inside a substorm wedge provides a source for the blobs. They are generated by a pulsed inward plasma and field transport under dipolarization of the magnetic field in regions of limited longitudinal extent. The question remains: what is the origin of the pulsed formation of a few minutes duration?

The lack of close correlation with the substorm activity excludes a connection with the major reconnection events underlying the substorms. Could it be small-scale, transient reconnections? Such a conjecture cannot be excluded, but it implies that the actual reconnection process was located further outward and sufficiently far away that breaking of the associated earthward reconnection jet had already occurred outside the position of Cluster (cf. Haerendel, 1992; Shiokawa et al., 1997). At this point, we have to ask ourselves whether such transient reconnection events might be facilitated by the presence of $\mathrm{O}^{+}$-ions, as proposed with respect to the onset of tearing instabilities in the tail current sheet by Baker et al. (1982,1989). Their argument was based on the increased ion gyroradius in comparison with the thickness of the plasma sheet. Was the $\mathrm{O}^{+}$presence, which is such a striking feature of the period under discussion, causal or coincidental for the high-beta events? The mass density of $\mathrm{O}^{+}$was about equal to that of the hydrogen plasma, thus affecting the overall inertia of the plasma. But in the light of our present understanding of the reconnection process (e.g. Shay et al., 1998; Hesse et al., 2001) which emphasizes the impact of the vast difference of the electron and ion inertia on the structure and dynamics of the diffusion region, it is hard to imagine that an increase in the ion mass density by

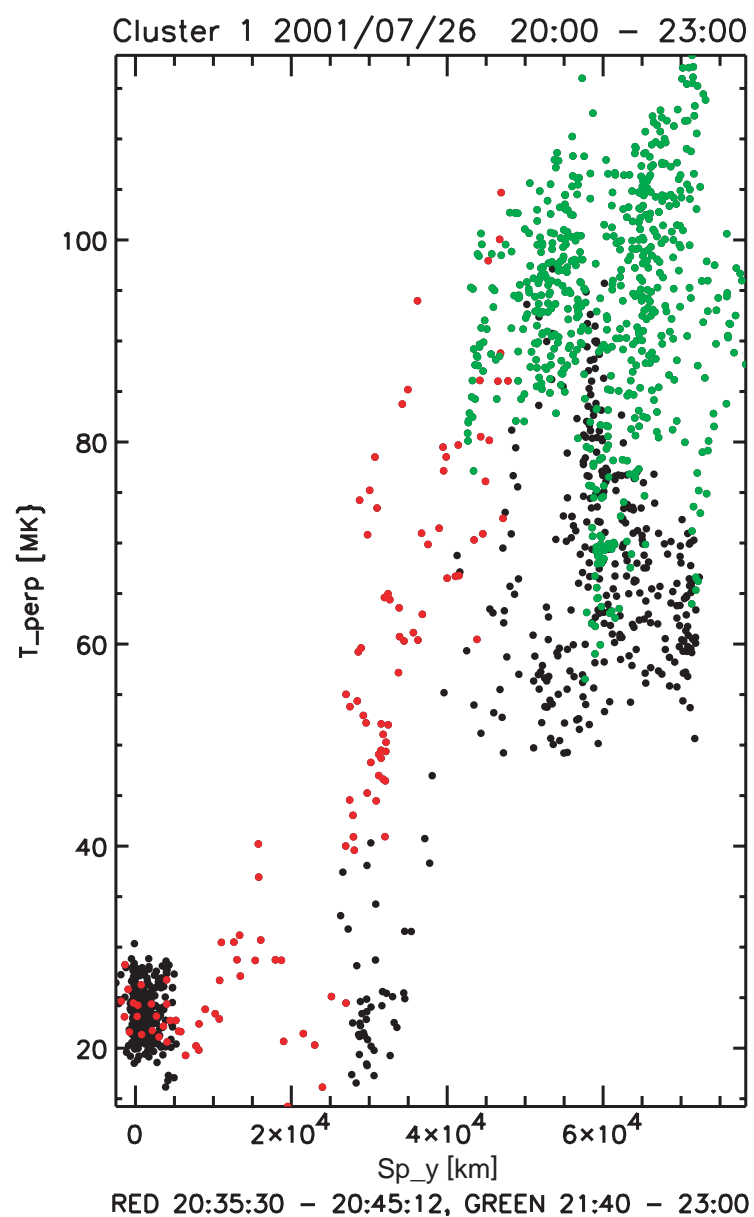

Fig. 13. Perpendicular proton temperature versus $S p-y$. The colors correspond to the time intervals marked in Fig. 12.

a factor of two would have severe dynamical consequences. We rather take the view that the $\mathrm{O}^{+}$-ions populating the eastern region of the substorm wedge do not play an important dynamical role. They are seen just as characteristics of the magnetosphere-ionosphere coupling processes driving fieldaligned currents, setting up potential drops, heating and accelerating ionospheric heavy ions up to several $\mathrm{keV}$ energy as observed here.

If we exclude transient reconnection, what else can trigger the dipolarizations and earthward transport? A convincing answer to this question must be consistent with four observational facts: (1) The high-beta events extend far beyond the recovery phase of the substorms (Fig. 1); (2) starting with event \#2 the total pressure decreases steadily (Fig. 3); (3) there is no substantial E-W, but only a mean earthward transport (Figs. 6 and 11); (4) the magnetic meridian plane is bent more strongly towards midnight during the events (Fig. 11). The first observation suggests that the events are rearrangements of plasma and field within the tail plasma sheet, but not fresh injections from a more distant reconnection line. If the latter occurred, we would expect an overall pressure increase, contrary to fact (2). Furthermore, the field should be distorted so as to diverge more strongly outward, in order 


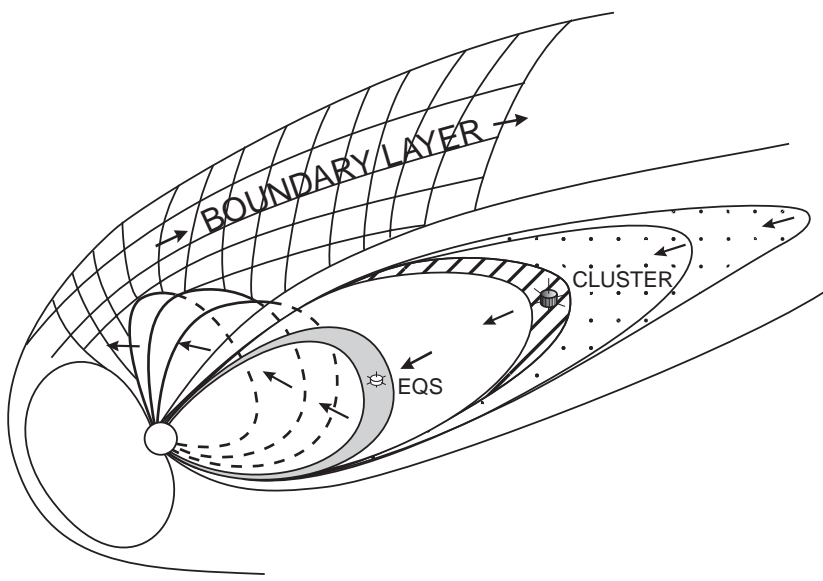

Fig. 14. Cartoon visualizing the suggested plasma transport by the high- $\beta$-events from the tail through the outer magnetosphere into the morning boundary layer.

to accommodate the increased plasma pressure. This is well illustrated in the simulations of Birn et al. (1999) for substorm injections. Observations (2) and (4) show clearly a steady and slow collapse of the plasma sheet. Finally, the fact that all plasma transport is directed earthward, more or less along the meridian plane, raises the question: where does it go to? The answer is to be found in the plasma blobs discovered between 9 and $11 R_{E}$ (see above), which are systematically moving towards later morning hours.

Vaivads et al. (2001b) have shown that the so-called plasma blobs or compressional Pc5 waves observed by Equator-S and Geotail (Haerendel et al., 1999; Vaivads et al., 2001a) are the magnetospheric counterpart of Ps6 compressional waves which are often associated with $\Omega$-bands or eastward moving auroral structures found during the recovery phase of substorms (e.g. Buchert et al., 1988). These luminous tongues protruding poleward from a diffuse auroral band are sites of upward field-aligned currents with maximum density of $1-2 \mu \mathrm{A} / \mathrm{m}^{2}$. Their eastward directed drift speed of typically $0.6 \mathrm{~km} / \mathrm{s}$ maps into speeds of $18-20 \mathrm{~km} / \mathrm{s}$ at $11 R_{E}$, consistent with the observed drifts of the plasma blobs. However, not all plasma blobs encountered outside $9 R_{E}$ must have optical counterparts, i.e. $\Omega$-bands. This may only apply in the true recovery phase of substorms, whereas during quiet periods, hours after a substorm, the field-aligned currents driven by the magnetospheric structures appear to be too weak to cause aurora (Haerendel et al., 1999).

If, as we suggest, the high-beta structures at $19 R_{E}$ are physically related to the high-beta plasma blobs at 9-11 $R_{E}$, how do we cope with the absence of an eastward drift at the outer location? There is a natural explanation for the apparently conflicting motions. The high-beta structures at $19 R_{E}$ are feeding the plasma blobs with fresh plasma out of the decaying substorm wedge while the eastward flow at 9-11 $R_{E}$ is removing the plasma towards the morning magnetopause. Here, the plasma may be injected into the boundary layer. Indeed, Haerendel et al. (1999) concluded from comparison with Geotail data (Nishida et al., 1997) that blobby structures persist out to the magnetopause.

We have several times drawn attention to the behavior of the $\varphi$-component of the magnetic field in the high-beta events at $19 R_{E}$. The same tendency was found inside the plasma blobs at 9-11 $R_{E}$ (see Haerendel et al., 1999, Fig. 5). It implies that the driving force of the eastward convection is not applied from further outside, but rather from low altitudes. The eastward flow at $L \leq 11$ is part of a large-scale, counterclockwise convection pattern dominating the polar ionosphere during substorms. The associated equivalent current system is named DP1. As the substorm subsides, the DP1 system prevails (see Kamide and Baumjohann, 1993, p. 105). It is characterized by a two-cell pattern, but during morning hours in the auroral oval the convection is eastward. All of this is driven by forces exerted on the ionosphere from the tail and night-side magnetosphere via field-aligned currents. The incompressibility of the near-Earth magnetic field enforces a plasma circulation that may, in certain regions, also drag the magnetospheric plasma with it, rather than being locally driven from above, for instance, by pressure gradients. This is the explanation we would like to offer for the behavior of the azimuthal field component inside the high-beta events. At the Cluster position, the deflated plasma sheet tends to collapse towards the midnight meridian, thus opposing any eastward-directed motion impressed from below.

The overall picture arising from this analysis and from a synopsis with the plasma blob/Pc5 behavior has been depicted into the cartoon of Fig. 14. The transport of plasma towards the morning magnetopause on field lines in the $L \cong 11$ range calls for a re-supply of magnetic flux and plasma which is still amply available in the former substorm current wedge. This triggers the observed earthward motion near $19 R_{E}$, which happens in pulsations consistent with the compressional Ps6 waves and, early in the recovery phase of substorms, with $\Omega$-bands further inward. The final whereabouts of the plasma remains terra incognita. Most likely, it mixes with plasma in the morning-side boundary layer where it is carried downstream and eventually released into the solar wind. This conjecture needs, of course, further investigation.

If the above chain of arguments is accepted, one is naturally forced to abandon the interpretation of the luminous plasma tongues and associated Ps6 pulsations as outward (poleward) protrusions of an existing hot plasma population and to reverse the direction of transport. Any earthward motion at large distances, as found in this reported data set, must not necessarily map into significant equatorward drifts in the ionosphere. The reason is that the high-beta structures may slowly lose their internal energy content by feeding a Poynting flux into the ionosphere and thus collapse. The associated inward transport of magnetic flux would appear as rather slow equatorward drift components of the order of $100 \mathrm{~m} / \mathrm{s}$ or below. The electric field measurements inside $\Omega$-bands reported by Buchert et al. (1988) show a dominance of a meandering around the tongues in the eastward direction and little systematic poleward or equatorward motion. Careful assessments of the overall radial transport direction and 
its association with the flux-tube displacements in the Ps6 waves are needed to either prove or disprove the conjecture put forward in this paper. Furthermore, an analysis of similar high-beta events encountered by Cluster and other spacecraft, as well as a closer inspection of structure and dynamics of the morningside magnetopause in the recovery and postrecovery phases of substorms are strongly suggested.

Acknowledgements. We are grateful to the technical and scientific personnel at MPE, Garching; CESR, Toulouse, UNH, Durham; IFSI, Frascati; IRF, Kiruna; MPA, Lindau; UCB, Berkeley; and UW, Seattle, who made the development of the CIS instrument possible. We thank the FGM, CIS, PEACE, RAPID teams on Cluster, the IMAGE FUV team, the IMAGE ground magnetometer network and the ACE team for using their data. The work at MPE in Garching is supported by DLR (Deutsches Zentrum für Luft und Raumfahrt) under contracts 50OC0102 and 50OC0104. The work in TU Braunschweig was supported by DLR under contract 500 C0103.

Topical Editor T. Pulkkinen thanks a referee for his help in evaluating this paper.

\section{References}

Akasofu, S.-I. and Kimball, D. S.: The dynamics of aurora, 1. Instabilities of the aurora, J. Atmos. Terr. Phys., 26, 205, 1964.

Baker, D. N., Hones Jr., E. W., Young, D. T., and Birn, J.: The possible role of ionospheric oxygen in the initiation and development of plasma sheet instabilities, Geophys. Res. Lett., 9, 1337, 1982.

Baker, D. N., Fritz, T. A., and Bernhard, P. A.: A small-scale plasmoid formed during the 13 May 1985, AMPTE magnetotail barium release J. Geophys. Res., 94, 17 084-17 096, 1989.

Balogh, A., Carr, C. M., Acuña, M. H., Dunlop, M. W., Beek, T. J., Brown, P., Fornacon, K.-H., Georgescu, E., Glassmeier, K.H., Harris, J., Musmann, G., Oddy, T., and Schwingenschuh, K.: The Cluster magnetic field investigation: overview of in-flight performance and initial results, Ann. Geophys., 19, 1207, 2001.

Baumjohann, W.: Spatially inhomogeneous current configurations as seen by the Scandinavian Magnetometer Array, in: Proceedings of the International Workshop on Selected Topics of Magnetospheric Physics, 34-40, Jpn. IMS Comm., Tokyo, 1979.

Baumjohann, W., Sckopke, N., LaBelle, J., Klecker, B., Lühr, H., and Glassmeier, K. H.: Plasma and field observations of a compressional Pc5 wave event, J. Geophys. Res., 92, 12 203-12 212, 1987.

Birn, J., Hesse, M., Haerendel, G., Baumjohann, W., and Shiokawa, K.: Flow braking and the substorm current wedge, J. Geophys. Res., 104, 1999.

Buchert, S., Baumjohann, W., Haerendel, G., La Hoz, C., and Lühr, H.: Magnetometer and incoherent scatter observations of an intense Ps6 pulsation event, J. Atmos. Terr. Phys., 50, 357-367, 1988.

Buchert, S., Haerendel, G., and Baumjohann, W.: A model for the electric fields and currents during a strong Ps6 pulsation event, J. Geophys. Res., 95, 3733-3743, 1990.

Escoubet, C. P., Russell, C. T., and Schmidt, R.: Cluster - Science and Mission Overview, Space Sci. Rev., 79, (1-2), 11-32, 1997.

Haerendel, G.: Disruption, ballooning or auroral avalanche - on the cause of substorms, in: Proceedings of the International Conference on Substorms (ICS-1), Kiruna, 416.420, ESA, 1992.

Haerendel, G., Baumjohann, W., Georgescu, E., Nakamura, R., Kistler, L. M., Klecker, B., Kucharek, H., Vaivads, A., Mukai,
T., and Kokubun, S.: High-beta plasma blobs in the morningside plasma sheet, Ann. Geophys., 17, 1592-1601, 1999.

Hasegawa, A.: Drift mirror instability in the magnetosphere, Phys. Fluids, 12, 2642-2650, 1969.

Hesse, M., Birn, J., and Kuznetsova, M.: Collisionless magnetic reconnection: Electron processes and transport modeling, J. Geophys. Res., 106, 3721-3735, 2001.

Kamide, Y. and Baumjohann, W.: Magnetosphere-ionosphere coupling, Springer Verlag, Berlin, 1993.

Nishida, A., Mukai, T., and Yamamoto, T.: Traversal of the nightside magnetosphere at $10-15 R_{E}$ during northward IMF, Geophys. Res. Lett., 24, 939-942, 1997.

Opgenoorth, H. J., Oksman, J., Kaila, K. U., Nielsen, E., and Baumjohann, W.: Characteristics of eastward drifting omega bands in the morning sector of the auroral oval, J. Geophys. Res., 88, 9171, 1983.

Pulkkinen, T. I., Pellinen, R. J., Koskinen, H. E. J., Opgenoorth, H. J., Murphree, J. S., Petrov, V., Zaitzev, A., and Friis-Christensen, E.: Auroral signatures of substorm recovery phase: A case study, in: Magnetospheric Substorms, Geophys. Monogr. Ser., 64, edited by Kan, J. R., Potemra, T. A., Kokubun, S., and Takesi, I., AGU, Washington D.C., 333-341, 1991.

Rème, H., Aoustin, C., Bosqued, J. M., Dandouras, I., Lavraud, B., Sauvaud, J. A., Barthe, A., Bouyssou, J., Camus, Th., CoeurJoly, O., et al.: First multispacecraft ion measurements in and near the Earth's magnetosphere with the identical Cluster ion spectrometry (CIS) experiment, Ann. Geophys., 19, 1303, 2001.

Rostoker, G. and Samson, J. C.: Can substorm expansive phase effects and low frequency Pc magnetic pulsations be attributed to the same source mechanism?, Geophys. Res. Lett., 11, 271-274, 1984.

Saito, T. and Yumoto, K.: Comparison of the two-snake model with the observed polarization of the substorm-associated magnetic pulsation Ps6, J. Geomagn. Geoelectr., 30, 39-54, 1978.

Shay, M. A., Drake, J. F., Denton, R. E., and Biskamp, D.: Structure of the dissipation region during collisionless magnetic reconnection, J. Geophys. Res., 103, 9165-9176, 1998.

Shiokawa, K., Baumjohann, W., and Haerendel, G.: Braking of high-speed flows in the near-Earth tail, Geophys. Res. Lett., 24, 1179-1182, 1997.

Steen, A., Collis, P. N., Evans, D., Kremser, G., Capelle, S., Rees, D., and Tsurutani, B. T.: Observations of a gradual transition between Ps6 activity with auroral torches and surgelike pulsations during strong geomagnetic disturbances, J. Geophys. Res., 93, $8713,1988$.

Vaivads, A., Baumjohann, W., Haerendel, G., Nakamura, R., Kucharek, H., Klecker, B., Lessard, M. R., Kistler, L. M., Mukai, T., and Nishida, A.: Compressional Pc5 type pulsations in the morningside plasma sheet, Ann. Geophys., 19, 311-320, 2001a.

Vaivads, A., Baumjohann, W., Georgescu, E., Haerendel, G., Nakamura, R., Lessard, M. R., Eglitis, P., Kistler, L. M., and Ergun, R. E.: Correlation studies of compressional Pc5 pulsations in space and Ps6 pulsations on the ground, J. Geophys. Res., 106, $29797-$ 29 806, 2001b.

Yamamoto, T., Makita, K., Ozaki, M., and Meng, C.-I.: A particle simulation of auroral omega bands and torch-like structure, J. Geomagn. Geoelectr., 45, 619, 1993.

Yamamoto, T., Inoue, S., and Meng, C.-I.: Formation of auroral omega bands in the paired region 1 and region 2 field-aligned current system, J. Geophys. Res., 102, 2531-2544, 1997. 